\title{
Bites by foreign venomous snakes in Britain
}

\author{
H A REID
}

arietans five, Agkistrodon rhodostoma three, Naja naja three, and the remaining 13 bites were caused by 10 different species (see table).

\section{Summary and conclusions}

In 1970-7 17 people in Britain were the victims of 32 bites by foreign venomous snakes. Crotalus atrox caused eight of these bites, Bitis arietans five, and the remaining 19 bites were caused by 12 different species. All the victims were bitten while handling the snake, and 24 bites were incurred by private individuals in their own homes. Poisoning was negligible in 17 of the 32 bites but lifethreatening in at least two cases. Thus in the early stages snake bite may be unpredictable as a clinical problem. All victims of snake bite should be observed for at least 12 hours to assess the severity of poisoning and to ensure rational treatment. Local necrosis developed in six cases and resulted in prolonged illness in five of these cases; local incision was carried out and may have been a causal factor. Comprehensive stocks of antivenoms for treating bites by foreign venomous snakes are held by the National Health Service in Liverpool and London.

Antivenom is indicated (a) for potentially serious systemic poisoning, as evidenced by hypotension, electrocardiographic changes, neutrophilia, and acidosis (after viper or elapid bites), abnormal bleeding or non-clotting blood after viper bites; and ptosis or glossopharyngeal palsy after elapid bites; and (b) for bites from snakes whose venom causes local necrosis, to prevent or minimise this unpleasant complication. For effective antivenom treatment intravenous infusion is mandatory.

\section{Introduction}

Bites by our native venomous snake, Vipera berus, may cause problems. Bites by imported venomous snakes are rarer but may cause even greater problems and entail police, ambulancemen, and even helicopters in transporting patients or antivenom across the country. The Department of Health and Social Security has recently designated Liverpool and London as main antivenom centres to hold comprehensive stocks of antivenoms for treating bites by foreign venomous snakes. It therefore seems appropriate to review a series of such bites inflicted in Britain during the 1970s.

\section{Bites by foreign venomous snakes}

During the 1970s I have been concerned in 32 cases of bites by foreign venomous snakes in Britain. Of the 17 victims, 12 were bitten once, two were bitten three times, one was bitten four times, and two were bitten five times. The victims' average age was 29 years (range 18-62), and only one was a woman. Three bites were received by zoo personnel; in five cases the victims worked in institutes obtaining venom for research, and the remaining 24 bites were incurred by private individuals in their homes. All the bites occurred when the victim was handling - or mishandling - the snake, and this was reflected in the site of the bites: four on the hand, two on the forearm, and 26 on finger or thumb. Crotalus atrox caused eight bites, Bitis

Liverpool School of Tropical Medicine, Liverpool L3 5QA H A REID, MD, FRCPE, consultant physician and senior lecturer
Snake species causing the 32 bites

\begin{tabular}{|c|c|c|c|c|c|}
\hline \multicolumn{2}{|c|}{$\begin{array}{c}\text { Group 1 } \\
\text { (no medical treatment } \\
\text { sought) }\end{array}$} & \multicolumn{2}{|c|}{$\begin{array}{c}\text { Group } 2 \\
\text { (hospital treatment: } \\
\text { antivenom not given) }\end{array}$} & \multicolumn{2}{|c|}{$\begin{array}{c}\text { Group } 3 \\
\text { (hospital treatment: } \\
\text { antivenom given) }\end{array}$} \\
\hline Species & $\begin{array}{c}\text { No of } \\
\text { bites }\end{array}$ & Species & $\begin{array}{l}\text { No of } \\
\text { bites }\end{array}$ & Species & $\begin{array}{l}\text { No of } \\
\text { bites }\end{array}$ \\
\hline $\begin{array}{l}\text { Agkistrodon } \\
\text { piscivorus } \\
\text { (cottonmouth) } \\
\text { Agkistrodon halys } \\
\text { (Pallas's viper) } \\
\text { Crotalus atrox } \\
\text { (Western } \\
\text { diamondback } \\
\text { rattlesnake) } \\
\text { Naja naja } \\
\text { (Asian cobra) } \\
\text { Trimeresurus } \\
\text { albolabris } \\
\text { (bamboo } \\
\text { snake) } \\
\text { Trimeresurus } \\
\text { wagleri } \\
\text { (Wagler's } \\
\text { temple viper) }\end{array}$ & $\begin{array}{l}1 \\
3\end{array}$ & $\begin{array}{l}\text { Agkistrodon } \\
\text { contortrix } \\
\text { (American } \\
\text { copperhead) } \\
\text { Agkistrodon } \\
\text { rhodostoma } \\
\text { (Malayan pit } \\
\text { viper) } \\
\text { Bitis arietans } \\
\text { (puff adder) } \\
\text { Crotalus atrox } \\
\text { Crotalus viridis } \\
\text { (Southern } \\
\text { Pacific } \\
\text { rattlesnake) } \\
\text { Echis carinatus } \\
\text { (carpet viper) } \\
\text { Naja naja } \\
\text { Rhabdophis } \\
\text { subminiatus } \\
\text { (red-necked } \\
\text { keelback) } \\
\text { Trimeresurus } \\
\text { zwagleri } \\
\text { Vipera ammodytes } \\
\text { (long-nosed } \\
\text { viper) }\end{array}$ & $\begin{array}{l}1 \\
1 \\
1\end{array}$ & $\begin{array}{l}\text { Bitis arietans } \\
\text { Crotalus atrox } \\
\text { Crotalus viridis } \\
\text { Vipera russelli } \\
\quad \text { (Russell's viper) }\end{array}$ & $\begin{array}{l}4 \\
3 \\
1 \\
1\end{array}$ \\
\hline
\end{tabular}

\section{Treatment}

Ten of the 32 bites produced negligible poisoning and no medical treatment was sought (group 1). Hospital treatment was given for the remaining 22 bites, and in over half the cases the victims reached hospital within one hour. Delays in reaching hospital of up to 20 hours, mainly because of delayed onset of poisoning, ${ }^{1}$ did not seriously affect the outcome.

BITES NOT TREATED WITH ANTIVENOM

Antivenom was not given for 13 of the 22 bites seen in hospital 을 (group 2). In six of these cases (two bites by $A$ rhodostoma; and one $N$ bite by each of $A$ contortrix, $C$ atrox, $C$ viridis, and Trimeresurus $D$ wagleri) poisoning was minimal and clearly did not warrant antivenom. 음 Systemic poisoning sufficient to indicate antivenom developed in four patients, bitten by $A$ rhodostoma (causing defibrination), by Echis $N$ carinatus (defibrination), by $N$ naja (T-wave inversion on electro- N cardiogram (ECG)), and by $V$ ammodytes (hypotension, white blood 0 cell count (WBC) $19.8 \times 10^{9} / 1$ ), but antivenom was witheld because the victims were sensitive to horse serum. Three of the patients recovered completely -in three days after the $V$ ammodytes bite, in 10 days after the $A$ rhodostoma bite, and 30 days after the $E$ carinatus bite. ${ }^{2}$ Local necrosis probably developed in the fourth patient, bitten $\frac{T}{0}$ by $N$ naja, as his hand showed the dusky discoloration around the bite $\stackrel{\mathbb{D}}{\mathbb{D}}$ marks typical of cobra bite necrosis, ${ }^{3}$ when he discharged himself $\Omega$ against medical advice three days after the bite.

Life-threatening poisoning developed (slowly) in one patient bitten by a red-necked keelback Rhabdophis subminiatus, ${ }^{1}$ but no known effective antivenom was available. $R$ subminiatus is back-fanged and was previously regarded as harmless to man; it is common in many parts of Asia.

In the two following cases in group 2 antivenom was not given but in retrospect it would probably have helped.

Case 1-A 23-year-old man put a dish of water into the cage of his three pet rattlesnakes, and his hand was promptly bitten. He was admitted to an intensive care unit one hour later. The three $C$ atrox specimens were only 
two months old. Abnormal bleeding did not occur but the patient developed a defibrination syndrome with plasma fibrinogen concentration of nil and a raised concentration of fibrin/fibrinogen degradation products (FDPs). His arm became massively swollen and the swelling spread on to his chest. Coagulation values returned to normal after nine days and the patient was discharged two weeks after the bite. Local necrosis did not develop. Antivenom would have shortened the duration of the coagulation defect and if given within two to three hours of admission should have lessened the amount and duration of swelling.

Case 2-A 23-year-old man was displaying his adult $B$ arietans $(90 \mathrm{~cm}$ long) to photographers when a camera flash appeared to upset the puff adder, which bit his owner's left middle and index fingers. He incised the site of both bites, applied a venous tourniquet, and, within half an hour of the bite, arrived at hospital, where the casualty officer made more local incisions. (These incisions may have contributed to the subsequent local necrosis.) No evidence of systemic poisoning, such as vomiting, abnormal bleeding, or hypotension, developed, and only the fingers and the back of his hand were swollen two hours after the bite. Antivenom was available but was not given because the effects of poisoning seemed to be entirely local. But his WBC on admission, reported the next day, was $15 \cdot 0 \times 10^{9} / 1$ with $86 \%$ neutrophils, and the following day had risen to $24.3 \times 10^{9} / 1$. Platelet counts; fibrinogen titres; prothrombin times; and plasma urea, electrolytes, and serum enzyme concentrations remained normal. The day after the bites his whole arm was swollen and a few blisters had appeared on the fingers. Local necrosis became increasingly evident, and both fingers were amputated. One and a half years later handgrip was excellent and the victim no longer regarded the lost fingers as an appreciable disability. An antivenom infusion within a few hours of admission would, however, probably have prevented local necrosis and the subsequent amputation. It was not given because a controlled trial in Malayan viper bite poisoning had shown that intramuscular antivenom reduced neither the incidence nor the severity of local necrosis. ${ }^{4}$ Later work has shown that antivenom does minimise local effects if infused intravenously within four to five hours of the bite. ${ }^{5-7}$

\section{BITES TREATED WITH ANTIVENOM}

Antivenom was given for nine of the 22 bites treated in hospital (group 3). In four cases the antivenom was injected intramuscularly (in one case because the antivenom pamphlet recommended intramuscular injection). Poisoning from $B$ arietans bite in one case was mild and the patient recovered completely in five days. Systemic poisoning was mild after two other $B$ arietans bites and after a $C$ atrox bite, but local necrosis developed in all three victims and full recovery took five weeks, eight months, and six weeks. It is most unlikely that the antivenom helped any of these patients, but if it had been infused intravenously local necrosis would probably have been prevented.

In five cases the antivenom was infused intravenously. A bite on the left hand by a $B$ arietans $65 \mathrm{~cm}$ long gave no systemic effects, although the whole arm and adjacent chest wall became swollen. Local necrosis did not develop and the patient had fully recovered two weeks after the bite. The contents of one ampoule of antivenom were infused but not until 44 hours after the bite; it is therefore unlikely that it affected the outcome. In cases 3 and 4, described below, antivenom shortened the duration of upset and probably prevented local necrosis.

Case 3-A 22-year-old zoo attendant was handling a 1-day-old $V$ russelli specimen and was bitten on a finger. Local pain and swelling started within a few minutes and his whole arm had become swollen 40 minutes after the bite. He vomited before reaching hospital, 70 minutes after the bite. His blood pressure was $150 / 90 \mathrm{~mm} \mathrm{Hg}$, WBC $18.3 \times 10^{9} / 1$, blood non-clotting, and fibrinogen titre nil. Police rushed five ampoules of Haffkine polyvalent antivenom up the motorway from London and the contents were infused intravenously four hours after the bite. The next morning coagulation had returned to normal. The patient recovered completely within two weeks.

Case 4-A 32-year-old man was bitten on his thumb while force-feeding an adult $C$ atrox $122 \mathrm{~cm}$ long for research. Local pain and swelling, nausea, and giddiness developed within a few minutes and he reached hospital 15 minutes after the bite. Gross swelling had spread up the forearm; WBC was $12 \cdot 0 \times 10^{9} / 1$, and coagulation values were normal. The patient had been asthmatic since childhood and was taking salbutamol. Poisoning appeared serious and posed the problem: was the risk of poisoning without antivenom greater than the risk of antivenom anaphylactic reaction? It was decided to give antivenom, and the contents of five ampoules of Wyeth polyvalent antivenom were infused together with hydrocortisone; the infusion started 30 minutes after the bite and ended two and a half hours later. No immediate reaction occurred. Local swelling subsequently extended only to the elbow, and envenoming effects resolved completely in five days. A late serum reaction (fever, erythema, enlarged lymph nodes, and joint pains) started six days after the bite and resolved within five days.

Case 5-A 29-year-old zoo attendant was bitten on his finger near the nail by a 10 -month-old $C$ atrox. The site was incised by ambulance staff. $\mathrm{He}$ reached hospital one hour after the bite, when WBC was $15.9 \times 10^{9} / 1$ and serum bicarbonate concentration $21.5 \mathrm{mmol}(\mathrm{mEq}) / 1$. He vomited three hour after the bite, when WBC had risen to $22.0 \times 10^{9} / 1$. Blood pressure and ECGs remained normal. The contents of five Wyeth antivenom ampoules were then infused. In the morning he felt better, WBC was $16.9 \times 10^{9} / 1(12$ hours after the bite), his platelet count and coagulation profile remained normal, serum creatine phosphokinase concentration was $405 \mathrm{IU} / 1$ (normal maximum $130 \mathrm{IU} / 1$ ), and FDP concentration was $60 \mathrm{mg} / 1$. Swelling reached the shoulder, and necrosis developed over $2 \mathrm{~cm}^{2}$ of the terminal phalanx; the underlying bone became affected and he took over nine months to recover completely. The antivenom probably minimised the systemic poisoning, but did not prevent local necrosis.

Case 6-A 34-year-old man was bitten on the forearm by his $C$ viridis rattlesnake (124 cm long). He reached hospital three hours later, and next morning, 12 hours after the bite, swelling had extended to the trunk. He had signs of severe systemic poisoning-appreciable weakness, sweating, blood pressure of $110 / 40 \mathrm{~mm} \mathrm{Hg}$, oozing blood from venepuncture sites, and vomiting of fresh blood. The Hess test result was negative and ECG normal. The urine contained both protein and blood. The WBC had risen from 12.9 to $21.0 \times 10^{9} / 1$. The fibrinogen titres remained normal but prothrombin time was 35 seconds and FDP concentrations were slightly raised. Wyeth antivenom (five ampoules) was infused 15 hours after the bite. Within a few hours the patient felt much better and oozing from venepuncture sites had stopped. Swelling was resolving without signs of necrosis when the patient discharged himself against medical advice three days after the bite. Although the antivenom was not given until 15 hours after the bite, it probably saved this patient's life.

\section{Discussion}

How many people in Britain keep foreign venomous snakes? A questionnaire survey showed that 11 out of 90 zoos did so in 1970-7 (59 species). Five-hundred members of herpetological societies were also questioned, and, of the 310 who replied, 26 said that they kept foreign venomous snakes ( 50 species). The commonest species were $C$ atrox, $B$ arietans, $B$ gabonica, and $N$ naja. Bites by venomous snakes in zoos are rare: in 1914-66 there were eight such bites (none fatal) among the staff of the London Zoological Society and no bites during the last 10 years (D J Ball, personal communication, 1977). Bites in private individuals are also unusual, but the resulting reactions may verge on the panic-stricken because of ignorance about the effects of snake bites.

\section{PROGNOSIS IN VENOMOUS SNAKE BITE}

In 1795 Felix Fontana ${ }^{8}$ confounded his colleagues by saying of viper bites in Europe "I am of the opinion that of 100 men bit ... not one would die, even though they should make use of no remedy." If Fontana had written "only one" instead of "not one," he would have been more correct. Despite these reassuring statistics, however, snake venom is highly toxic and virtually every venomous snake could kill an adult if it injected its maximum venom yield with a bite. Fortunately, this happens rarely, ${ }^{9}$ but because the difference between a negligible dose for man and a lethal dose is a matter of only a few drops snake bite as a clinical problem is highly unpredictable in the early stages.

In the present series of 32 bites poisoning was negligible or non-existent after 17 bites (10 in group 1 , six in group 2 , and one in group 3) but was near-fatal in at least two cases. This emphasises the importance of observing all victims for at least 12 hours to assess the severity of poisoning and ensure rational treatment.

\section{MANAGEMENT}

Fontana also condemned local incision of viper bites because this caused gangrene. ${ }^{8}$ In the present series local necrosis developed after six bites (three $B$ arietans bites, two $C$ atrox bites, and one $N$ naja bite), and in five of these local incision had been carried out. Local necrosis usually causes prolonged morbidity and sometimes permanent disability.

First-aid, pre-hospital, and hospital procedures for adder bite in Britain, which have been reviewed recently, ${ }^{10}$ are also suitable for dealing with bites by foreign venomous snakes. But if local necrosis, which does not occur after adder bites, becomes obvious sloughs should be excised (conservatively). Systemic 
antimicrobials are then usually needed. Skin grafting should be prompt even if infection is still evident.

It is important not to panic: there is plenty of time in Britain to administer antivenom if indicated. Local effects may be minimised or prevented if antivenom is infused up to five hours after the bite, and for reversing systemic effects it is virtually never too late for successful antivenom treatment (see case 6) Nevertheless, it is important not to dismiss a bite as trivial without adequate observation, preferably in an intensive care unit.

Additional monitoring ${ }^{10}$ in cases of foreign venomous snake bites should include observation for local necrosis (skin darkness, blisters, and smell) and signs of systemic poisoning. These signs include hypotension, ECG changes, neutrophilia, and acidosis after viper or elapid bites; ptosis, difficulty in speaking or swallowing, and breathing changes after elapid bites; and abnormal bleeding or non-clotting blood after viper bites.

Non-clotting blood after the $C$ atrox bite in case 1 was unexpected because several authorities have found that $C$ atrox venom does not affect coagulation in in-vitro tests. Venom samples were therefore collected from three $C$ atrox specimens as they aged from 2 to 22 months. Up to eight months the venom defibrinated animals by a direct thrombin-like action on fibrinogen, but from one year onwards venom samples no longer affected coagulation. ${ }^{11}$ The coagulation profile of the patient bitten by a 10 -month-old $C$ atrox specimen (case 5) remained normal (also normal in case 4 ).

Defibrination as confirmed by the clottability or clot-quality test $^{1: 2}$ is usually a sensitive clinical (not laboratory) sign of systemic envenoming, because a minute amount of venom in the circulation can cause total defibrination. For example, with $A$ rhodostoma venom the minimum defibrinating dose in in-vivo experiments was only one-thousandth of the intravenous lethal dose. ${ }^{13}$ In contrast, the defibrinating activity of juvenile $C$ atrox venom is relatively feeble (experimentally the minimum defibrinating dose is roughly the lethal dose for mice) and therefore non-clotting blood in $C$ atrox victims suggests that the patient has received a potentially lethal or near-lethal dose of venom and urgently requires effective antivenom therapy. ${ }^{11}$

\section{ANTIVENOM}

In February 1978 the Department of Health and Social Security designated Liverpool (Walton Hospital in conjunction with the Liverpool School of Tropical Medicine) and the National Poisons Information Centre, London, as centres for holding comprehensive stocks of antivenoms (Health Notice (78) 13). These stocks provide, so far as possible, "world coverage" for treating bites by foreign venomous snakes kept by zoos and by private individuals in Britain.

Antivenom is not needed if little or no venom has been injected, as happened in over half of these cases. Antivenom should be given if there is potentially serious systemic poisoning or if the bite was from a snake whose venom causes local necrosis, such as the Asian cobras ( $N$ naja), African spitting cobra ( $N$ nigricollis), the African puff adder ( $B$ arietans), many rattlesnakes (Crotalus), or tropical American vipers (Bothrops). When victims of bites by this type of snake are seen within four to five hours of the bite and have swelling extending up the limb (showing that venom has been injected) antivenom should be considered.

Intravenous infusion is essential for effective antivenom treatment. Infusion is much safer than bolus injection, which often causes reactions through activating complement. ${ }^{14}$ The pamphlets accompanying commercial antivenoms are often misleading in suggesting that antivenom should be given automatically to every victim of snake bite, and none deal satisfactorily with the indications for giving antivenom. The necessity for the intravenous route and for infusion is rarely emphasised enough, and the dose advised is often too low. In general, larger amounts of antivenom (usually at least 10 ampoules) are needed in elapid envenoming because antivenoms are less potent in neutralising elapid compared with viper venoms. In viper envenoming producing defibrination, follow-up observation of clot quality is useful in assessing whether enough w antivenom has been given.

A table of foreign venomous snakes kept in Britain during 1970-7 C indicating species known to cause and not to cause non-clotting blood $\vec{F}$ in human envenoming is available from me. Health Notice (78) $13, \stackrel{0}{\stackrel{9}{9}}$ giving details of antivenoms may be obtained from: DHSS Store, 0 Scholefield Mill, Brunswick Street, Nelson, Lancashire BB9 0HU.

I thank the many patients and colleagues who helped me through $\stackrel{\widehat{\Phi}}{\varrho}$ correspondence and by allowing me to include their cases; the police on for excellent service in delivering antivenom; and Mrs Heather Huxley for secretarial work.

\section{References}

1 Mather, $\mathrm{H} \mathrm{M}$, Mayne, S, and McMonagle, T M, British Medical fournal, $1978,1,1324$

${ }^{2}$ Reid, H A, British Medical fournal, 1977, 2, 1326.

${ }^{3}$ Reid, H A, British Medical fournal, 1964, 2, 540.

${ }^{4}$ Reid, H A, Thean, P C, and Martin, W J, British Medical fournal, 1963, छ 2, 1378.

5 Christensen, P A, South African Medical fournal, 1969, 43, 1253 .
6 Warrell, D A, Ormerod, L D, and Davidson, N McD, British Medical fournal, 1975, 4, 697.

7 Theakston, R D G, and Reid, H A, Lancet, 1976, 2, 121.
${ }^{8}$ Fontana, F, Treatise on the Venom of the Viper, 2nd edn, trans J Skinner, vol 2, p 47 and 38. London, Cuthell, 1795.

9 Cooper, J E, and Reid, H A, Transactions of the Royal Society of Tropical $\vec{\omega}$ Medicine and Hygiene, 1976, 70, 264.

10 Reid, H A, British Medical fournal, 1976, 2, 153.

${ }^{11}$ Reid, H A, and Theakston, R D G, American fournal of Tropical Medicine and Hygiene. In press.

12 Reid, H A, Chan, K E, and Thean, P C, Lancet, 1963, 1, 621.

${ }^{13}$ Reid, H A, in Animal Toxins, ed F E Russell and P R Saunders, p 323. Oxford and New York, Pergamon Press, 1967.

14 Sutherland, S K, Medical fournal of Australia, 1977, 1, 613.

How common is postpuerperal diastasis of the symphysis pubis, and what is the treatment?

During pregnancy many women have some degree of separation of the symphysis pubis, and its significance is missed. The pain over the $\delta$ joint is often put down to the fetal head, but more careful examination can show tenderness over the symphysis. For the pubic bones to $ᄋ$ separate to any pronounced degree the sacroiliac joints must also open up. If the sacroiliac joints are tightly closed then the pubic bones must $\mathcal{N}$ remain apposed through the symphysis. Therefore with diastasis $D$ backache is almost invariably traceable to the sacroiliac joints, and it should be inquired for. After birth the whole pelvis usually tightens $\mathbb{N}$ once more without special management, but some patients will need a rather longer time in bed, preferably on fracture boards, than is $\omega$ usual nowadays. They do not normally get it and are unwilling to suffer the temporary inconvenience. In so doing they may store up a long history of low back pain, arising mainly in the sacroiliac joints.

A very few patients are seriously incapacitated after birth and may $\stackrel{\mathscr{C}}{\rightarrow}$ be almost unable to walk. They may need about three weeks in bed $\tau$ with attempts to make their pelves close up, using non-stretch $\bar{O}$ bandages firmly wound round the bones, especially over the great trochanters and the symphysis. Some have advocated using a canvas $\vec{D}$ sling under the buttocks with each end crossed over the other and attached to weights slung over pulleys on a Balkan beam. Only rarely does such treatment by rest fail. A minute number of patients may carry their problem for much longer. The symphysis and the sacroiliac joints remain unstable. Conservative treatment as suggested (but perhaps prolonged for several weeks) should probably be the first line. 을 But when all else fails operation to stabilise the pelvis may have to be seriously considered, and the right place to attack will probably be the hindmost joints of the pelvic girdle, but very careful assessment is needed, and the symphysis too may need some form of internal stabilisation. 